\title{
Factors associated with needle stick and sharp injuries, among healthcare workers in Felege Hiwot Referral Hospital, Bahir Dar, Northwest Ethiopia: facility based cross-sectional survey
}

\author{
Lulie Walle $^{1}$, Emebet Abebe ${ }^{2}$, Medihanit Tsegaye ${ }^{2}$, Hanna Franco ${ }^{2}$, Dereje Birhanu ${ }^{3}$, Muluken Azage ${ }^{3}$ \\ 1.North Gondar ADA Zonal office RH/MNCH project coordinator, Gondar Ethiopia. \\ 2. Amhara Region, Felege Hiwot Referral Hospital, Bahir Dar, Ethiopia
}

3. Bahir Dar University, College of Medicine and Health Sciences, Department of Public Health, Bahir Dar, Ethiopia

doi: 10.3396/JIIC.v9i4.030.13

\begin{abstract}
Needle stick and sharp injuries are occupational health hazards to healthcare workers. Every day they are exposed to deadly pathogens through contaminated needle and other sharps injuries. The aim of this study was to assess the prevalence and factors associated with needle stick and sharp injuries among healthcare workers in Felege Hiwot Referral Hospital.

Facility based cross-sectional survey was conducted from 1-5 July 2012, using questionnaire. All healthcare workers contacted in the study period were included. Data was analyzed using SPSS version 16.0. Binary logistic regression was used to identify factors associated with needle stick and sharp injuries.

From the total 332 healthcare workers enrolled, 216 (65.1\%) were females. Nearly $2 / 3^{\text {rd }}$ were diploma holders, and Nurse by profession. Hundred three (31.0\%) had needle stick and sharp injury at least once in the previous 12 months. Three fourth of the injuries were due to needle stick. Those whose monthly income was $>=1000.00$ Eth Birr, satisfied on their job, and worked in waste handling unit were likelyu 4.1, 2.8, and 4.1 more likely to get injured than their counterparts respectively (Adjusted Odds ratio $[A O R]=4.1,95 \%$ Confidence Interval $[\mathrm{Cl}]$ 1.27-13.14, $\mathrm{AOR}=2.78,95 \% \mathrm{Cl}$ 1.01-7.63, and $\mathrm{AOR}=4.1,95 \% \mathrm{Cl}$ 1.27-13.14). Those who worked in maternity unit were $80 \%$ less likely to get injured than those who worked in Emergency units (AOR= 0.20, 95\% Cl 0.05-0.78).

Nearly $1 / 3^{\text {rd }}$ of participants had needle stick and sharp injury at least once in the previous year. Suboptimal practices and behaviours that put them at risk to the injury were identified. Authorities should give on job training, and regular supportive supervision. Further research is needed to determine the incidence of the injury, and the type of disease they would acquire.
\end{abstract}

Keywords: Needlestick injuries and epidemiology; Occupational exposure; health personnel

\section{Corresponding author}

Dereje Birhanu

Bahir Dar University, College of Medicine and Health Sciences, Department of Public Health.

Email: firedereje@gmail.com 


\section{Introduction}

Needle stick and sharp injuries (NSIs) are common health hazards that occurred in the working environment. Research findings on needle stick injury indicated that it ranged from $21 \%$ to $95 \%$. $^{1}$ These preventable injuries expose healthcare workers to over 20 different blood borne pathogens, and resulted in 1000 infections per year. ${ }^{2}$ Needle stick injury accounted for $86 \%$ of all occupationally related infection transmissions. The most common blood borne pathogens transmitted with NSIs are hepatitis B, hepatitis $\mathrm{C}$ and HIV. ${ }^{3-4}$ The World Health Organization (WHO) has reported that worldwide $2.5 \%$ of HIV, and $40 \%$ of hepatitis B and C cases among healthcare workers were due to occupational exposure. ${ }^{5}$

On average, healthcare workers (HCWs) in Africa suffer two to four needle stick injuries per year. ${ }^{6}$ According to CDC, up to $86 \%$ of needle stick injuries can be prevented using safer needle devices. ${ }^{7}$ The extent of the problem and factors associated to its occurrence is limited in the study area. Therefore, the study aimed to assess the magnitude of the problem, and factors associated to needle stick and sharp injury among healthcare workers at Felege Hiwot Referral Hospital (FHRH), Bahir Dar Ethiopia.

\section{Methods and materials}

Facility based cross-sectional survey was conducted from 1 to 5 July 2012 to assess the magnitude of and factors associated to needle stick and sharp injury among HCWs. The study was conducted at Felege Hiwot Referral Hospital, Bahir Dar, Ethiopia, located $565 \mathrm{Km}$ Northwest of Addis Ababa. HCWs included in the study were doctors, health officers, nurses, midwifes, laboratory personnel, and waste handlers. All HCWs contacted during the study period were included in the study. The Hospital has been established in 1963 and is currently a Referral Hospital serving more than 5 million people, offering different types of health care services to the surrounding community. It has a total of 287 beds and about 500 clients visited the health facility daily. ${ }^{8}$

\section{Data collection tools}

Anonymous self administered questionnaire was used to collect the data. The questionnaire elicits information on $\mathrm{HCW}$ s demographic characteristics, frequency/nature of exposures, and the risk factors for occupational exposures. The questionnaire was initially constructed in English and was subsequently translated into the local language Amharic and was then re-translated into English via an expert who was fluent in both languages. The questionnaire was pretested before the actual data collection. Four clinical nurses were recruited to facilitate the data collection process and one day training was given.

\section{Variables of the study}

Occurrence of needle stick and sharp injury in the previous 12 month was the dependent variable, and Socio-demographic variables such as age, sex, job category, level of education, occupation, work experience, behavioural factors such as needle recapping, risk perception, awareness on diseases transmission by shapes injury, job satisfaction, reporting pattern, use of personal protective equipment, and working environment such as health safety training, length of working hours/week, existence of safety guidelines, availability of sharp disposal containers, working department, presence of work guidelines were the independent variables.

\section{Data quality assurance}

Pretested questionnaire was used to collect the data and training was given to the data collection facilitators. Moreover the collected data was checked for completeness daily by supervisors.

\section{Data processing and analysis}

The data was coded and entered into EPI INFO version 6 statistical packages, and then exported to SPSS version 16.0 for analysis. Binary logistic regression analysis was carried to identify the predictors of needle stick and sharp injury. Independent variables that had a $p$-value less than or equal to 0.2 were entered in to multivariate logistic regression model (backward stepwise procedure) to control confounders. The strength of association of predictor variables was assessed using odds ratio and $\mathrm{P}$ - value $\leq 0.05$ at $95 \%$ $\mathrm{Cl}$ was considered statistically significant. The findings of the study were presented in text and tables.

\section{Ethical considerations}

Ethical clearance was obtained from ethical review board of College of Medicine and Health Science, 
Bahir Dar University. Permission was obtained from Hospital administrators. Verbal consent was obtained from each participant after the objective of the study was explained. Participants were also informed that all data obtained from them was kept confidential by using codes instead of any personal identifiers.

\section{Result}

Socio demographic characteristics of study participants A total of $332 \mathrm{HCWs}$ were enrolled in to the study, of whom 216 (65.1\%) were females. The majority $(86.7 \%)$ were Orthodox Christian by religion, and nearly two third $(62.3 \%)$ were diploma holders by qualification, $71.4 \%$ were clinical Nurses by profession, and $63.3 \%$ were married. One hundred eighty nine HCWs had five years or less work experience (Tabel I).

\section{Working environment, injury exposure,} and related characteristics

Majority of the respondents (91.6\%) were concerned about the health risks of needle stick and sharp injury, of whom the risk was perceived high in 297 (89.5\%) of the respondents. Nearly two thirds $(63.7 \%)$ had recapped the needle at least once, and one third $(34.7 \%)$ had recapped the needle using two hands. Nearly all respondents (98.5\%) knew the diseases transmitted through needle stick and sharp injury. Regarding to the degree of the injury, $113(57.7 \%)$ respondents replied that the injury they suffered was superficial. Respondents reported that emergency conditions and unexpected patient movement during the procedure were the main reasons to the occurrence of the injury. Nearly half, 107 (46.1\%) of

Table I: Socio demographic characteristic of health care workers $(n=332)$

at Felege Hiwot Referral Hospital, Bahir Dar, Northwest, Ethiopia, 2012

\begin{tabular}{lrr} 
Variables/Response & Frequency & Percent \\
\hline Sex of respondent & & \\
\hline Male & 116 & 34.9 \\
\hline Female & 216 & 65.1 \\
\hline Age of respondent & & \\
\hline $20-24$ & 27 & 8.2 \\
\hline $25-29$ & 154 & 46.5 \\
\hline $30-34$ & 85 & 25.7 \\
\hline $35-39$ & 36 & 10.9 \\
\hline $40+$ & 29 & 8.7 \\
\hline Religion & & \\
\hline Orthodox & 288 & 86.7 \\
\hline Muslim & 19 & 5.7 \\
\hline Protestant & 25 & 7.5 \\
\hline
\end{tabular}

\section{Educational status}

\begin{tabular}{lrr}
\hline Read and write & 12 & 3.6 \\
\hline Primary education(1-8) & 7 & 2.1 \\
\hline High school (9-10) & 23 & 6.9 \\
\hline Technical and vocational & 5 & 1.5 \\
\hline Diploma & 207 & 62.3 \\
\hline Degree and above & 78 & 23.5 \\
\hline Marital status & & \\
\hline Married & 210 & 63.3 \\
\hline Unmarried & 122 & 36.7 \\
\hline
\end{tabular}

\begin{tabular}{lrr} 
Variables/Response & Frequency & Percent \\
\hline Profession/Job category & & \\
\hline Janitors/cleaners & 45 & 13.6 \\
\hline Nurses & 237 & 71.4 \\
\hline Health Officers & 13 & 3.9 \\
\hline Laboratory personnel & 10 & 3.0 \\
\hline Medical Doctor & 21 & 6.3 \\
\hline Anaesthetist & 6 & 1.8 \\
\hline
\end{tabular}

\begin{tabular}{lrr}
\hline Service year & & \\
\hline <5years & 189 & 56.9 \\
\hline 6-10years & 78 & 23.5 \\
\hline$>=10$ years & 65 & 7.2 \\
\hline
\end{tabular}

\section{Currently working Department}

\begin{tabular}{lrr}
\hline Emergency unit & 71 & 21.4 \\
\hline Paediatric ward & 43 & 13.0 \\
\hline Maternity ward & 48 & 14.5 \\
\hline Laboratory Unit & 13 & 3.9 \\
\hline Operation theatre unit & 30 & 9.0 \\
\hline Medical Ward & 51 & 15.1 \\
\hline Surgical Wards & 39 & 11.7 \\
\hline Waste handlers unit & 37 & 11.1 \\
\hline
\end{tabular}

Monthly income (1US \# =18.50 Ethiopian Birr)

\begin{tabular}{lrr}
$<1000$ Eth Birr & 64 & 19.3 \\
\hline 1000 Eth Birr & 268 & 80.7 \\
\hline
\end{tabular}


Table II: Participant's behaviour, and working environment among health care workers

in Felege Hiwot Referral Hospital, Bahir Dar, Northwest Ethiopia July 2012.

Question/Response

Frequency Percent

Were you concerned about the risk of needle stick/sharp injury

Yes

304

91.6

No

28

How do you rate the risk of needle stick/ sharps injuries

Not risky

Low risk

Moderate risk

High risk

Do you think needle stick or sharps injury is avoidable?

Yes

No

38

11.4

Do you think disease is transmitted by needle $\&$ sharp injuries

Yes

No

5

Did you recap needles after use?

Never

Sometimes

Mostly

All the time

How do you recap the needles after use

With one hand

Using two hands

Do you use personal protective equipments?

Yes

Was safety box available at your work place?

Yes

Did you receive medical care after injury? $(n=195)$

Yes

No

91

Did you report your injury to concerned body?

Yes

No

Reason for not reporting $(n=103)$

I don't think it is important to report

Fear of stigma

Thought patient was low risk for HIV

Were safety guidelines available at your work Env't? 
Question/Response

Frequency

Percent

Was working guidelines available at your work place?

Yes

251

75.6

No

81

24.4

Was there protocol for reporting the injury in your organization?

Yes

284

74.7

No

84

\section{Ever had training on occupational health safety?}

Yes

154

46.4

No

178

53.6

Number of hours worked/week

Up to 40 hours

96

28.9

More than 40 hours

236

Are you satisfied on your job

Yes

No

80

Are you satisfied with the working environment

yes

220

66.3

No

112

33.7

the participants who sustained the injury didn't report the injury to the concerned body. Among those who didn't report, in $12.6 \%$ of them, the reasons mentioned was that they perceived the patient had low risk of being HIV positive. Nearly $90 \%$ of participants replied safety box was available at their work place. From the total participants, 178 (53.6\%) reported that they had training on infection prevention (Table II).

Regarding to injury exposure: Of the total respondents, $62(18.7 \%), 103(31.0 \%)$, and $196(59.0 \%)$ had experienced needle stick and/or sharp injury at least once in the last 2 weeks, 12 months, and in their entire job career respectively. Of those who ever sustained the injury, 104 (53.1\%) were exposed more than once. More than three fourths of the injuries were caused by needle stick and it was superficial in $87 \%$ of the participants (Table III).

\section{Regarding to the factors associated} to needlestick and sharp injury

Healthcare workers whose monthly income was $>=1000.00$ Eth Birr (1US Dollar $=18.50$ Eth Birr) were 4 times more at risk to sustain a needle stick and sharp injury than those whose average monthly income was less than 1000.00 Eth Birr (AOR=4.08, $95 \% \mathrm{Cl} 1.27-13.14)$. Those who were satisfied on their job were about 3 times more likely to sustain needle stick and sharp injury than those who were not satisfied on their job (AOR=2.78, 95\% Cl 1.017.63); and those who worked in waste handling unit were 4 times more likely to experience needle stick and sharp injury than those who worked in Emergency Unit (AOR=4.08, 95\% Cl 1.27-13.14); but those who worked in the maternity ward were $80 \%$ less likely to get injured by needle stick and sharp injury than those who worked in emergency unit $(A O R=0.20,95 \% \mathrm{Cl}$ $0.05-0.78)$. Those who previously notify their injury were $77 \%$ less likely to encounter the injury than those who didn't notify to the concerned body (AOR=0.33, $95 \% \mathrm{Cl} 0.15-0.71)$. Availability of safety box at work place, infection prevention training, professional qualification, and utilization of personal protective devices were not statistically significant (Table IV).

\section{Discussion}

Healthcare workers are at risk to occupational health hazards mainly due to accidental exposure to injuries such as needle stick and/or other sharp materials. Among HCWs, the prevalence of needle stick and 
sharp injury in the previous twelve months prior to the survey was $31 \%$, implying that, needlestick and sharp injuries are common occupational health hazards to HCWs in the study area. The finding is higher when compared to studies done in Switzerland, Malaysia, \& South Africa where the proportion of injury in the last 12 months was $9.7 \%, 23.5 \%$, and $23.5 \%$ respectively. ${ }^{9-11}$ It is in line with a study done in Germany (31.4\%). ${ }^{12}$ But the proportion was lower than studies done in United Kingdom, Ethiopia, SSA, Egypt and India where the prevalence of needle stick and sharp injury reported were 38\%, 51.6\%, 57\%, 67.9\% and $80.1 \%$ respectively. ${ }^{13-17}$ The possible difference in the proportion of injury could be the study design used, the socio-demographic/economic status, and cultural characteristics of study participants. Also it could be due to the difference in the study health facility set ups, and even the year of the study. But whatever is the difference in the proportion of needle stick and sharp injury, healthcare workers are at much higher risk to acquire blood borne pathogens such as HIV and other infectious diseases through needle stick and sharp injuries.

In this study, the majority of HCWs who sustained needle stick and sharp injury were Nurses. It is in agreement with a study done in Egypt, ${ }^{16}$ and it is much higher as compared to studies done in Switzerland, South Africa, SSA, Nigeria, and Saudi Arabia. ${ }^{9-10,15,18-19}$ The possible difference may be due to the job description given to nurses where in Ethiopia a lot of exposure-prone procedures such as medication administration, and wound care are handled by nurses. At the same time the ratio of nurse to patient is not proportional as set by the WHO. Therefore Ethiopian Nurses in general, and Felege Hiwot referral Hospital nurses in particular, are more likely to get exposed to such injuries than nurses who worked in another country.

The study results revealed that needle stick was the major cause for the injury (77.3\%). It is in agreement with a study done in South Africa. ${ }^{10}$ The fact that HCWs were mainly injured by needle stick, may be due to inappropriate needle handling practice and/or might have poor perception in infection prevention. Regarding to the frequency of the injury, $75.7 \%$ of participants had experienced the injury once, and $24.3 \%$ more than once. The study is almost in agreement to a study done in Egypt. ${ }^{16}$ Implying that HCWs might practice recapping and/or might dispose of needles inappropriately. In the study area the practice of needle recapping after use is still prevalent among HCWs, where almost three fourths of the respondents $(74.7 \%)$ reported that they were recapping the needles immediately after use, and from them one third (34.7\%) were recapping using two hand technique. The practice of recapping was almost similar to studies done in India and in Nigeria. ${ }^{17-18}$

Considering the non reporting practice of health care workers to the concerned body, from the study participants $53.9 \%$ didn't report their injury to higher officials. This proportion is higher than that reported from Germany and UK ${ }^{12-13}$ but lower than that from Malaysia, Egypt, and Nigeria..116,18 Participants were asked why they didn't report to the concerned body, and the reasons as to why they didn't report were; I don't think it is important to report (81.6\%), and patient looks low risk for HIV (12.6\%). But it is a wrong perception because a person who looks healthy doesn't mean he/she is free from communicable diseases such as HIV, Hepatitis B and C, and in developing countries like ours, due to high HIV prevalence and no adequate vaccination access to hepatitis $B$ and $C$, it is important to consider everybody is at risk, and therefore precaution should be taken not to infect himself/herself and/or others.

Health care workers whose monthly income was $>=1000$ Eth Birr ( 1 US Dollar = 18.50 Ethiopian Birr) were 4 times more likely to encounter needle stick and sharp injury than those whose monthly income was below 1000 Eth Birr. This may possibly be since they have high professional qualification, they are suppose to engage in invasive procedures and/or work overload, and even might have extra works in private health institutions or within the government institution itself so that might put them at more risk to such injuries than their colleagues.

Healthcare workers who were satisfied on their job were nearly three times more at risk to encounter sharp injury than those who were not satisfied on their job. Possibly may be due to the fact that, since they were satisfied on their job, they might be involved in different hospital activities, and/or might be eager in 
Table III. Needle and sharp injury handling method

of health care workers $(n=332)$ at Felege Hiwot Referral Hospital, July, 2012

Question/Response

Frequency Percent

Ever experience needle \& sharp injury in your entire job $(n=332)$

\begin{tabular}{llr} 
Yes & 196 & 59 \\
No & 136 & 41 \\
\hline
\end{tabular}

Frequency of injury experienced in entire job career $(n=196)$

Once

$92 \quad 46.9$

More than once

104

53.1

Needle \& Sharps injury occurred in the last 2 weeks $(n=332)$

Yes

62

18.7

No

270

81.3

Frequency of injury occurred in last 2 weeks $(n=62)$

Once

More than once

46

25.8

Needle \& Sharp injury occurred in last 12 months $(n=332)$

Yes

No

229

Frequency of sharp injury in last 12 months $(n=103)$

Once

More than once

25

24.3

Material caused the injury

Needle

Lancet/Scalpel/blade

Glass/other sharp objects

Type of injury sustained

Deep

Superficial

helping and caring for patients that could lead them to be at much higher risk than those who were not satisfied in their job.

Participants who sustained superficial injury were three times more to encounter needle stick and sharp injury than those who sustained deep injury. Possibly those who sustained superficial injury might consider the incidence of the injury is less risky and/or even might forget the previous injury exposure because they might consider such superficial injury could not lead them to acquire the disease so may not take care to protect themselves from accidental injury than those who sustained deep injury.
Those who worked in waste handling unit were four times more likely to sustain needle stick and sharp injury than those who worked in emergency unit. This could be due to the nature of their work where most waste products produced during patient management may not be stored appropriately before being disposed and also they collect waste from different departments. At the same time the reason could be the professional or working area difference, where those who worked in the emergency unit could be health professionals who could have better knowledge on infection prevention than those who worked in waste handling unit. 
Table IV. Factors associated with occurrence of sharp injury among Health care worker in Felege Hiwot Referral Hospital, Bahir Dar Ethiopia, 2012

\begin{tabular}{|c|c|c|c|c|}
\hline \multirow[t]{2}{*}{ Variable Response } & \multicolumn{2}{|c|}{$\begin{array}{l}\text { Needle stick \& Sharp } \\
\text { injury in the last } 12 \\
\text { months }\end{array}$} & \multicolumn{2}{|c|}{$95 \%$} \\
\hline & Yes & No & COR & AOR \\
\hline \multicolumn{5}{|l|}{ Average monthly income } \\
\hline$<1000$ Eth Birr & 26 & 38 & 1 & 1 \\
\hline$>=1000$ Eth Birr & 77 & 191 & $1.69(0.97-2.99)$ & $4.1(1.27-13.14)^{* *}$ \\
\hline \multicolumn{5}{|l|}{ Get care after injury } \\
\hline Yes & 68 & 36 & $0.33(0.18-0.59)^{*}$ & $0.75(0.32-1.80)$ \\
\hline No & 35 & 56 & 1 & 1 \\
\hline \multicolumn{5}{|c|}{ Report injury to higher officials } \\
\hline Yes & 72 & 53 & $0.3(0.17-0.52)^{*}$ & $0.33(0.15-0.71)^{* *}$ \\
\hline No & 31 & 76 & 1 & 1 \\
\hline \multicolumn{5}{|l|}{ Job satisfaction } \\
\hline Yes & 67 & 185 & $2.26(1.34-3.81)^{*}$ & $2.78(1.01-7.63)^{* *}$ \\
\hline No & 36 & 44 & 1 & 1 \\
\hline \multicolumn{5}{|c|}{ Satisfaction on working Env't } \\
\hline Yes & 59 & 161 & $1.77(1.09-2.86)^{*}$ & $0.93(0.38-2.27)$ \\
\hline No & 44 & 68 & 1 & 1 \\
\hline \multicolumn{5}{|c|}{ Department currently working } \\
\hline Emergency unit & 19 & 52 & 1 & 1 \\
\hline Paediatric Ward & 12 & 31 & $1.06(1.13-5.96)$ & $0.73(0.24-2.22)$ \\
\hline Maternity & 13 & 35 & $2.45(0.97-6.19)$ & $0.20(0.053-0.78)^{* *}$ \\
\hline Operation theatre room & 1 & 19 & $2.13(0.58-8.16)$ & $0.29(0.08-1.02)$ \\
\hline Medical ward & 17 & 34 & $1.64(0.61-4.38)$ & $0.49(0.16-1.51)$ \\
\hline Surgical ward & 9 & 30 & $1.89(0.79-4.52)$ & $1.16(0.36-3.77)$ \\
\hline Waste handler Unit & 18 & 19 & $3.16(1.18-8.46)^{*}$ & $4.1(1.27-13.14)^{* *}$ \\
\hline
\end{tabular}

*-significant at COR, **-significant at AOR

Health care workers who notified the occurrence of the injury to the concerned body before the survey were $77 \%$ less likely to be exposed to needle stick and sharp injury than those who didn't report after they encountered the injury. This could be due to the fact that those who reported to the concerned body could have been advised from higher officials so that they learn from their previous exposure and also might be reminded from families/relatives not to encounter such an injury again so that could take more safety measure than those who didn't report.
Those who sustained needle stick injury were 90\% less likely to encounter another injury than those who had injury by other sharp objects. This could be explained by the fact that, healthcare workers might consider needle as the main vehicle for disease transmission than other sharp injuries. Therefore those who sustained needle injury might consider them more at risk and might take more prevention action than those who sustained injury due to other types of injury materials. 
Those who worked in the maternity ward were $80 \%$ less likely to get injured by needle stick and sharp objects than those who worked in Emergency unit. This could be explained in that since mothers are in labour, risk of high blood contamination is expected and maternity unit might have better access to protective equipments than emergency department. In addition at emergency unit cases would come unexpectedly and may need immediate intervention, at this time, healthcare workers might give less attention on utilization of personal protective equipments, but rather might rush up to save the life of the people.

\section{Limitation of the study}

Cross sectional study by its nature cannot establish cause and effect relationship. Since participants have been asked a one year exposure experience, there might be recall bias.

\section{Conclusion and recommendation}

This study revealed that one third of study participants had needle stick and sharp injury at least once in the previous 12 months. Nurses were more affected than other healthcare workers. Even though majority of respondents were concerned about risk of needle stick and sharp injury, and nearly all knew the diseases transmitted through it, one third of the study participants were recapping the needle using two-hand techniques. Monthly income, job satisfaction, and working in waste handling unit were the predictors for needle stick and sharp injury. On job training should be given to healthcare workers, and hospital administrators should create room for discussion on how to alleviate the problem. Further research is needed to determine the actual incidence of needle stick and sharp injury exposure, and the type of disease they would acquire.

\section{Acknowledgement}

We would like to acknowledge the administrators of Felege Hiwot Referral Hospital for permitting us to conduct the research. Our gratitude goes to study participants. We also thank the language editor.

\section{References}

1. Port C, Handelman, McGovern P. Needle stick injuries among healthcare workers. A literature review. AAOHNJ 1999; 47(6): 237-44.
2. Singru SA, Banerjee A. Occupational exposure to blood and body fluids among health care workers in a teaching hospital in Mumbai, India. Indian / Community Med 2008; 33(1): $26-$ 30. http://dx.doi.org/10.4103/0970-0218.39239

3. Rezaeian M, Asadpour M, Khademrezaeian H. Epidemiology of occupational exposure to needlestick and body fluids among doctors and medical students in Rafsanjan University of Medical Sciences. JOHE 2012; 1(1): 44-49.

4. Shah R, Fancy M, Nayak S, Bhavesh N. Knowledge and awareness regarding needle stick injuries among helath care workers in tertiary care hospital in Ahmedabad, Gujarat. National Journal of Community Medicine 2010; 1(2): 93-96.

5. WHO. World health report; reducing risk, promoting health life. Geneva, Switzerland, 2002.

6. Prüss-Ustün A, Rapiti E, Hutin Y. Estimation of the global burden of disease attributable to contaminated sharps injuries among health-care workers. Am J Ind Med 2005; 48(6): 482490. http://dx.doi.org/10.1002/ajim.20230

7. Rubian. Needle stick injury. Who bear the bear the brunt? Available at http://www.syringesneedles.org/blunt-syringeneedles-needle-stick-injury-who-bears-the-brunt/.

8. The third quarter annual report of Felege Hiwot Referal Hospital. 2011/2012.

9. Voidea C, Darlinga KEA, Kenfak-Foguenaa A, Erarda $V$, Cavassinia M, Lazor-Blanchetb C. Underreporting of needlestick and sharps injuries among healthcare workers in a Swiss University Hospital. Swiss Med Wkly 2012; 142: w13523.

10. The pattern of sharps injury to health care workers at Witbank Hospital. SA Fam Pract 2009; 51(2): 148-151.

11. Lekhraj Rampal GR, Rosidah Z, Whye Sook L, Azhar Z. Needle stick and sharps injuries and factors associated among health care workers in a Malaysian hospital. European Journal of Social Sciences 2010; 13(3): 354-362.

12. Wicker S, Jung J, Allwinn R, Gottschalk R, Rabenau HF. Prevalence and prevention of needle stick injuries among health care workers in a German University Hospital. Int Arch Occup Environ Health 2007; http://dx.doi.org/10.1007/ s00420-007-0219-7

13. Elmiyeh B, James MJ, Chahal CAA, Galea A, Alshafi K. Needle-stick injuries in the National Health Service: a culture of silence. J R Soc Med 2004; 97: 326-327. http://dx.doi. org/10.1258/jrsm.97.7.326

14. Neima A, Abera K. Assessment of the prevalence and determinants' of NSIs among Ethiopian nurses in five regional states. Ethiopian Nursing Association. May 2008.

15. Tarantoll L. A descriptive retrospective study of 567 accidental blood exposures in healthcare workers in three West Africa countries. Journal of Hospital Infection 2005; 60(3): 276-282. http://dx.doi.org/10.1016/j.jhin.2004.11.025

16. Hanafi MI, Mohamed AM, Kassem MS, Shawki M. Needle stick injuries among health care workers of University of Alexandria hospitals, Egypt. EMHJ 2011; 17(1).

17. Muralidhar S, Singh PK, Jain RK, Malhotra M, Bala M. Needle stick injuries among health care workers in a tertiary care hospital of India. Indian J Med Res 2010; 131: 405-410.

18. Bolarinwa OA, Asowande A, Akintimi Cl. Needle stick injury pattern among health workers in Primary health care facilities in Ilorin, Nigeria. Academic Research International. SAVAP International, www.savap.org.pk Volume 1, Issue 3, Nov 2011.

19. Hashmi A, Al Reesh SA, Indah L. Prevalence of needlestick and sharps injuries among healthcare workers, Najran, Saudi Arabia. Epidemiol 2012; 2: 117. http://dx.doi. org/10.4172/2161-1165.1000117 